\title{
ANALYSIS OF DEAD-TIME EFFECTS IN MULTI-PHASE VOLTAGE SOURCE INVERTERS
}

\author{
G. Grandi, J. Loncarski \\ Department of Electrical Engineering \\ University of Bologna, Italy
}

Keywords: Switch dead-time, voltage distortion, multi-phase inverter, harmonic analysis, inverter nonlinearity.

\begin{abstract}
Inverter dead-time effects have been investigated in past for three-phase voltage source inverters. Also, there have been some studies about multi-phase (more than three phase) inverters with reference to multi- phase drives. Recently, a great deal of research has concentrated on PWM methods suitable for multi-phase VSIs. All PWM methods theoretically produce sinusoidal output voltages without low-order harmonics. This paper analyzes the dead-time effects on output variables of voltages source inverters if no any compensation technique is applied. In particular, an overview of three-phase inverters is considered first. Then, a generalized extension to multiphase inverters is proposed and investigated in details. Theoretical analysis has shown that particular low-order harmonics appear as result of dead-times, and simulation results confirm the proposed analytical approach.
\end{abstract}

\section{Introduction}

Pulse-width modulation inverters have widely been used in motor drives. However, these inverters produce voltage distortion due to nonlinear characteristics of switching devices such as turn-on/turn-off times, voltage drops on switches and diodes. A further important non-linearity is caused by necessary dead-time introduced o avoid the so-called shoot-through of the dc link. In fact, to guarantee that both switches never conduct simultaneously, a small time delay is added to the gate signal of the turning on device. This small time, in order of $\mu$ s, introduces magnitude and phase errors in the output voltage. The voltage distortion increases with switching frequency, introducing harmonic components that may cause instabilities and additional losses in the machine being driven. Relative voltage deviation effect is more significant for smaller inverter output voltages [1]-[5].

The dead-time problem has already been investigated by the industry [2], [3] and various solutions have been proposed. In most cases the compensation techniques are based on an average value theory, the lost volt-seconds are averaged over an entire period and added to the commanded value. A pulsebased compensation method has been proposed in [2], where the compensation is realized for each pulse. The compensation voltages in [3] are calculated by using dead-time, switching period, current command and dc-link voltage. Re- gardless of the method used, all dead-time compensation techniques are based on polarity of the current. This is especially true around the zero-crossing where an accurate measurement is needed to correctly compensate for the dead- time. In [4] an on-line dead-time compensation technique is presented, acquiring the additional computation burden to determine the phase angle of currents.

The area of multiphase variable-speed motor drives, in general, and multiphase induction motor drives, in particular, has experienced a substantial growth since the beginning of this century. Detailed overview of the current state-of-the-art in this area is given by [6]. The inverter dead-time effect on the steady-state and dynamic performances of a multi-phase induction machine with current control is analyzed in [7]. The paper suggests a modified current control scheme that is able to compensate inverter dead-time and provides sinusoidal currents. Although in this case it is possible to have perfect compensation of dead-times, the problem remains for the drives that are based on machine flux estimation, since dead-time introduces errors if input dc voltage and switch patterns are used for calculations instead of actual ac output voltages. Analysis and compensation method for a five-leg inverter driving two three-phase ac motors independently has been done in [8]. Practically, this analysis can be simplified as for three-phase inverters, since the motors are independent.

Even though the compensation of dead-times can be done on bases of measurement of current, never it is perfect since the turn-on/turn-off times are not known exactly and are depending on many factors [9], leading to either an overcompensation or undercompensation.

This paper firstly presents a brief review of the dead-time effects in three-phase inverters, which is almost well known and investigated. Then, a generalized extension to n-phase inverters is given, analyzing the low-order harmonics introduced in output phase voltages. Finally, it has been verified by numerical simulations what is the effect on output voltage of fiveand seven-phase inverters, as examples of multi phase inverters, getting results in good agreement with the proposed theoretical developments.

\section{Review of dead-time effect in 3-phase VSI}

The typical three-phase PWM inverter with a passive load is shown in Fig. 1(a). Fig. 1(b) shows a one leg PWM converter. It is convenient to analyze the dead-time effects from one phase leg converter and then to extend the results to more legs (phases). During the dead-time $t_{d}$, both of the switching de- 


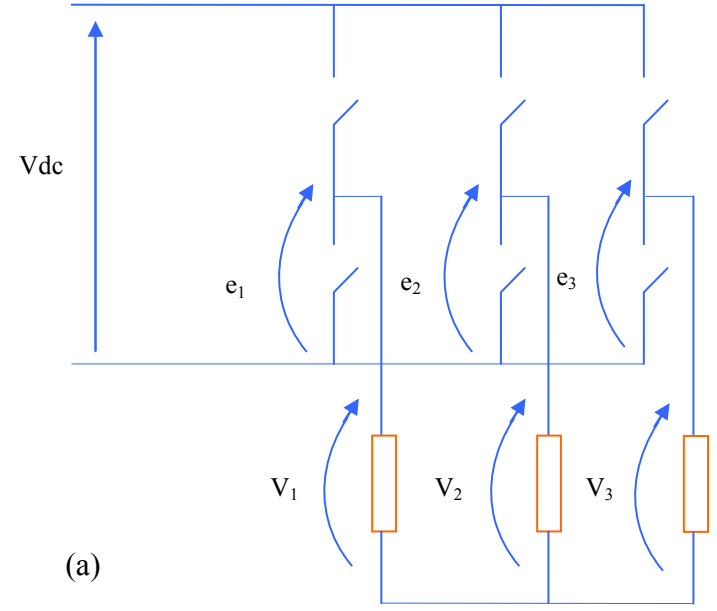

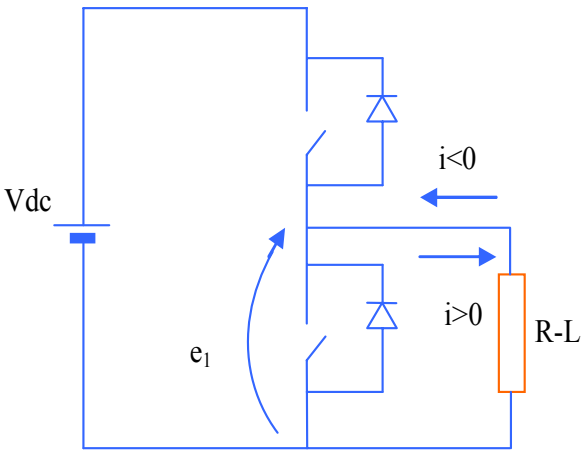

(b)

Fig. 1. Three-phase PWM inverter (a), and one-leg converter (b) with passive load (R-L).

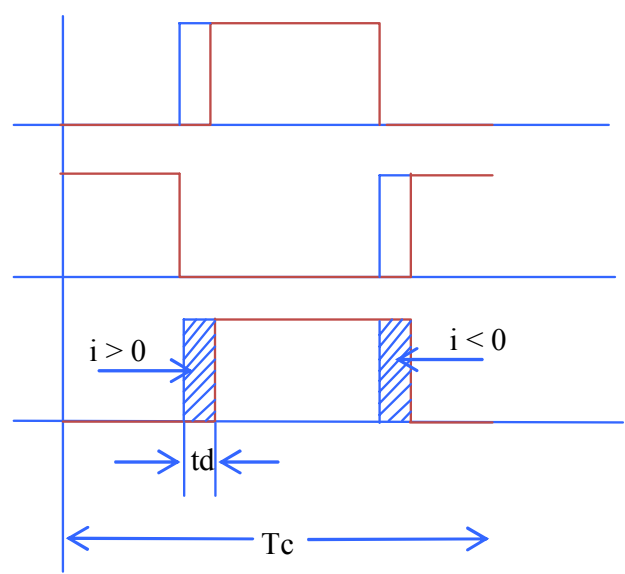

Fig. 2. Switching patterns and output voltages

vices in Fig. 1(b) cease to conduct, and one of the two diodes conducts. If the current polarity is positive, the lower diode will conduct, otherwise the upper diode will conduct.

The corresponding switching patterns and output voltages are shown in Fig. 2. The ideal gating pattern is shown in blue colour. However, in practical applications, the turn-on time of each switch is delayed by the dead-time $t_{d}$, leading to the real gating signals shown in red colour.

The actual pole voltage of $k$-th leg $(k=1,2,3), e_{k}$, can be evaluated on the basis of the reference pole voltage, $e_{k}{ }^{*}$, according to the direction of the phase current $i_{k}$ as:

$e_{k}=e_{k}^{*}-\operatorname{sign}\left(i_{k}\right) \Delta V_{d}$,

where $\Delta V_{d}$ is the averaged voltage contribution due to the dead-time $t_{d}$ over the switching period $T_{c}, \Delta V_{d}=t_{d} / T_{c} V_{d c}$.

It is assumed that the system is balanced in further analysis. The effects on three-phase inverters can be emphasized on the basis of the actual load voltage $v_{\mathrm{k}}$ expressed by pole voltages:

$v_{k}=e_{k}-\left(e_{1}+e_{2}+e_{3}\right) / 3$.

Introducing in (2) the actual pole voltages (1) leads to $v_{k}=v_{k}^{*}+u_{k}$,

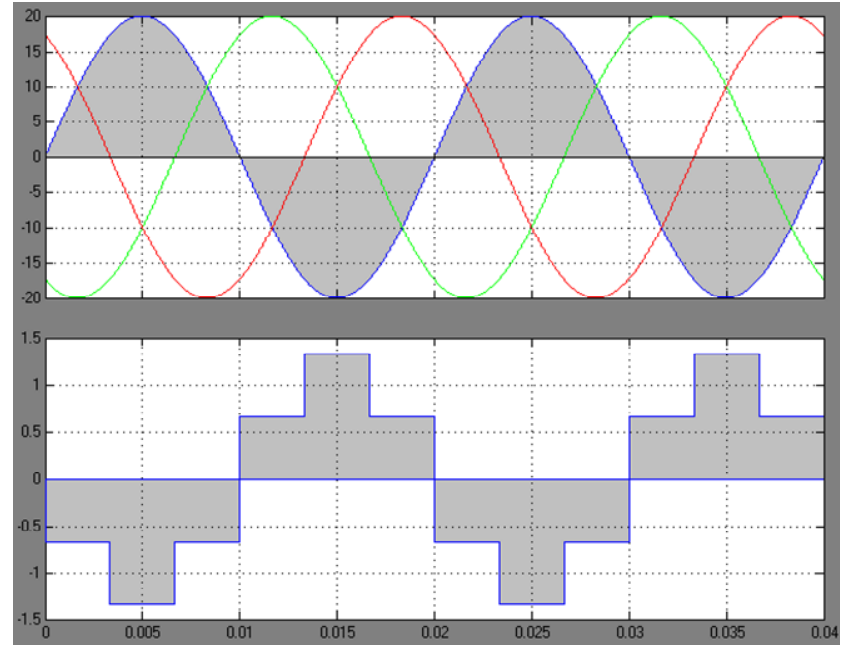

Fig. 3. Currents $i_{k}$ (top) and load voltage error $u_{1}$ (bottom, normalized with respect to $\Delta V_{d}$ ) for three-phase inverters.

being $v_{k}{ }^{*}$ the reference load voltage

$v_{k}^{*}=e_{k}^{*}-\left(e_{1}^{*}+e_{2}^{*}+e_{3}^{*}\right) / 3$,

and $u_{k}$ the average load voltage error introduced by dead-time

$u_{k}=\Delta V_{d}\left\{-\operatorname{sign}\left(i_{k}\right)+\left[\operatorname{sign}\left(i_{1}\right)+\operatorname{sign}\left(i_{2}\right)+\operatorname{sign}\left(i_{3}\right)\right] / 3\right\}$.

The time diagram $u_{k}(t)$ is depicted in Fig. 3 for the first phase $(k=1)$, considering three-phase sinusoidal balanced load currents, $i_{k}=I_{M} \sin \left[\omega_{o} t-(k-1) 2 \pi / 3\right]$, being $\omega_{o}=2 \pi / T$. In this case, the harmonics content of load voltage error developed as Fourier series, as also mentioned in [9], is

$$
\begin{aligned}
& u_{k}=-\Delta V_{d} \frac{4}{\pi}\left\{\sin \left[\omega_{o} t-(k-1) \frac{2 \pi}{3}\right]+\frac{1}{5} \sin \left[5\left(\omega_{o} t-(k-1) \frac{2 \pi}{3}\right)\right]\right. \\
& +\frac{1}{7} \sin \left[7\left(\omega_{o} t-(k-1) \frac{2 \pi}{3}\right)\right]+\frac{1}{11} \sin \left[11\left(\omega_{o} t-(k-1) \frac{2 \pi}{3}\right)\right] \\
& \left.+\frac{1}{13} \sin \left[13\left(\omega_{o} t-(k-1) \frac{2 \pi}{3}\right)\right]+\frac{1}{17} \sin \left[17\left(\omega_{o} t-(k-1) \frac{2 \pi}{3}\right)\right]+\ldots\right\}
\end{aligned}
$$




\section{Extension to n-phase inverters}

Equation (2) can be generalized to multi-phase inverters as:

$v_{k}=e_{k}-\frac{1}{n} \sum_{j=1}^{n} e_{j}, \quad k=1,2, \ldots, n$

where $v_{k}$ and $e_{k}$ are load and pole voltages, and the number of phases $n \geq 3$ is odd integer.

Equation (7) together with (1) leads to

$v_{k}=v_{k}^{*}+u_{k}$,

being

$$
v_{k}^{*}=e_{k}^{*}-\frac{1}{n} \sum_{j=1}^{n} e_{j}^{*},
$$

$u_{k}=\Delta V_{d}\left[-\operatorname{sign}\left(i_{k}\right)+\frac{1}{n} \sum_{j=1}^{n} \operatorname{sign}\left(i_{j}\right)\right]$.

The voltage error expressed by (10) can be seen as the sum of two contributions: the first one corresponds to a simple unity square wave signal with period $T$, whereas the second one corresponds to a square wave signal with amplitude $1 / n$ and period $T / n$, as shown in Fig. 4 (a) and (b), respectively.

By considering also in this case sinusoidal balanced currents $i_{k}=I_{M} \sin \left[\omega_{o} t-(k-1) 2 \pi / n\right]$, the Fourier development of the load voltage error can be obtained as a combination based on these two signals, leading to

$$
\begin{aligned}
& u_{k}=\Delta V_{d} \frac{4}{\pi}\left\{-\sin \left[\omega_{o} t-(k-1) \frac{2 \pi}{n}\right]-\frac{1}{3} \sin \left[3\left(\omega_{o} t-(k-1) \frac{2 \pi}{n}\right)\right]\right. \\
& -\frac{1}{5} \sin \left[5\left(\omega_{o} t-(k-1) \frac{2 \pi}{n}\right)\right]-\ldots .+\frac{1}{n} \sin \left[n\left(\omega_{o} t-(k-1) \frac{2 \pi}{n}\right)\right]+ \\
& \left.\frac{1}{3 n} \sin \left[3 n\left(\omega_{o} t-(k-1) \frac{2 \pi}{n}\right)\right]+\frac{1}{5 n} \sin \left[5 n\left(\omega_{o} t-(k-1) \frac{2 \pi}{n}\right)\right]+\ldots\right\}
\end{aligned}
$$

where $\omega_{0}=2 \pi / T$ is the fundamental frequency.

It can be noted that all harmonic components of the second signal completely erase with corresponding harmonics of the first signal, leading to the following simplified expression

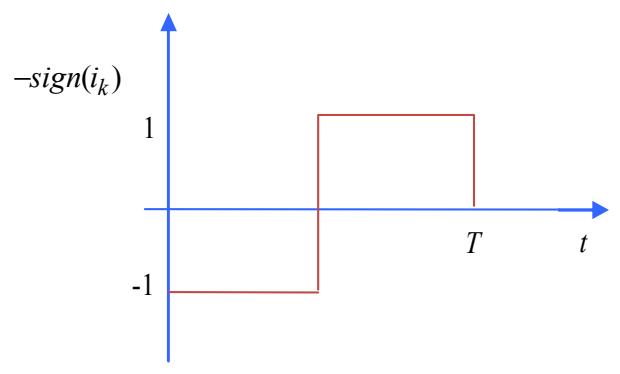

(a)
$u_{k}=-\Delta V_{d} \frac{4}{\pi} \sum_{h=1}^{\infty} \frac{1}{h} \sin \left[h\left(\omega_{o} t-(k-1) \frac{2 \pi}{n}\right)\right]$,

where $h$ is odd integer not multiple of $n$. Equation (12) states that the harmonic spectrum of voltage error introduced by dead-time $t_{d}$ almost coincides with the one of a square wave signal having period $T$ and amplitude $\Delta V_{d}$, just the harmonics with order multiple of the phase number are missing.

The amplitude of harmonics is calculated according to (12):

$U_{h}=\frac{4}{\pi} \frac{1}{h} \Delta V_{d} . \quad(h$ odd integer not multiple of $n)$

Note that harmonics amplitude is independent of both output voltage amplitude and load power factor $(P F=\cos \phi)$, but it depends on the dead-time duration $t_{d}$ only.

\section{Effect of load power factor on output voltage}

As mentioned above, the output voltage error depends on the current direction, which is a function of the load power factor. The amplitude of fundamental voltage error is given by (13) with $h=1$ :

$U_{1}=\frac{4}{\pi} \frac{t_{d}}{T_{c}} V_{d c}$

Defining the amplitude of the output voltage reference $V^{*}$ as function of modulation index $m$ :

$V^{*}=m V_{d c}$

enables calculation of the fundamental of the load voltage $V$ on the basis of the load power factor as [1]

$V=-U_{1} \cos \phi+\sqrt{V^{* 2}-U_{1}^{2} \sin ^{2} \phi}$.

From (16) is possible to evaluate the amplitude of fundamental voltage error as

$\left.U_{1}\right|_{1,2}=\frac{-2 V \cos (\phi) \pm \sqrt{4 V^{2} \cos ^{2} \phi+4\left(V^{* 2}-V^{2}\right)}}{2}$,

where just one solution is acceptable. Eq. (17) can be used with simulation results to calculate $U_{1}$ on the basis of $V^{*}, V$, and $\cos \phi$. This value can be compared to the one given by (14).

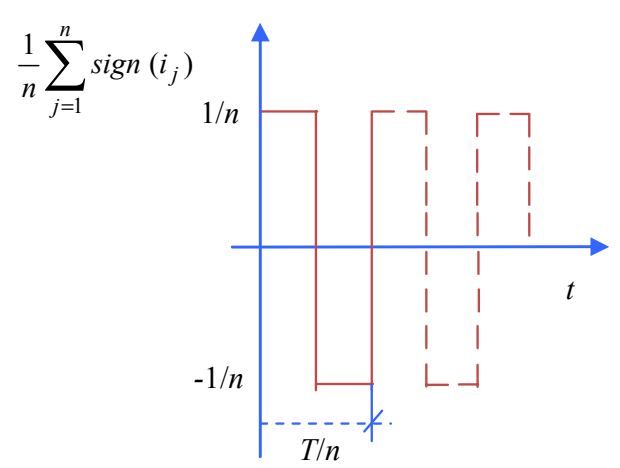

(b)

Fig. 4. Waveforms of the two contributions to the voltage error $u_{k}$ normalized with respect to $\Delta V_{d}$. 


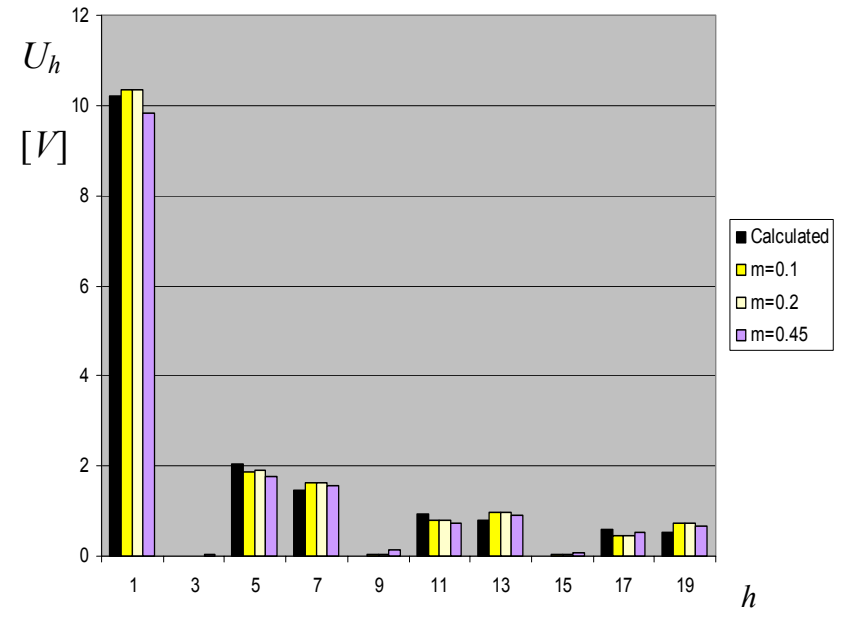

(a) $P F=1$

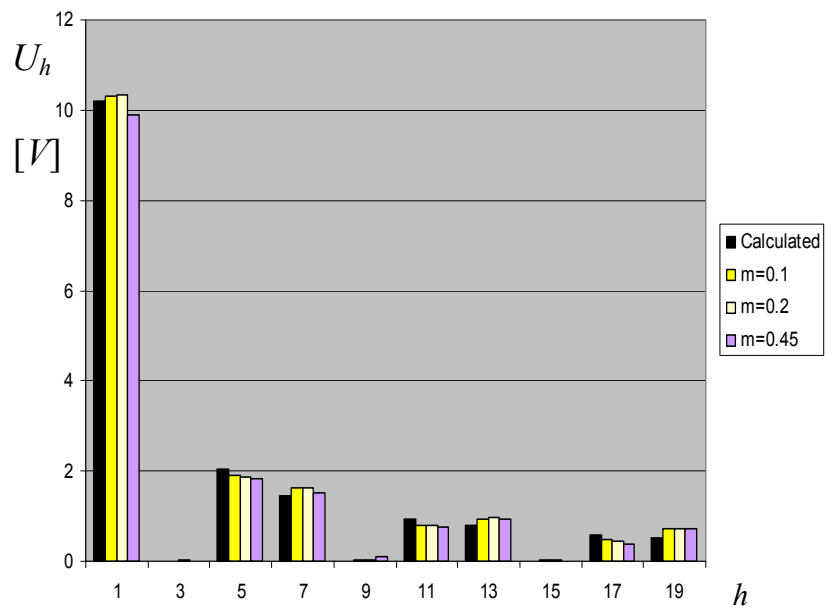

(b) $P F=-1$

Fig. 5. Harmonic spectrum of voltage error obtained by theory (calculated) and by circuit simulation for three-phase inverter with different modulation indexes and load power factors.

\section{Numerical verification}

In order to verify the theoretical developments shown in previous sections, circuit simulations are carried out by SimPowerSystems of Matlab considering three-, five- and sevenphase inverters supplying sinusoidal balanced current sources having $f=50 \mathrm{~Hz}, I_{M}=20 \mathrm{~A}$.

The dead-time duration is $t_{d}=20 \mu \mathrm{s}$, the switching frequency is $1 / T_{c}=2 \mathrm{kHz}$, and the dc voltage supply is $V_{d c}=200 \mathrm{~V}$.

A couple of relevant cases are considered in relation with different load power factors: load current in phase with voltage $\left(\phi=0^{\circ}, P F=1\right)$ and load current in opposite phase with voltage $\left(\phi=180^{\circ}, P F=-1\right)$.

Furthermore, different values of modulation index $m$ are investigated $(0.1,0.2,0.45)$. The harmonic spectrum of the voltage error is shown in all cases up to $19^{\text {th }}$ harmonic component.

\subsection{Three-phase inverters}

The output voltage error introduced by dead-time in threephase inverters is considered first, with reference to Section 2. In particular, Fig. 5 shows the harmonic spectrum of voltage error calculated by theory (black column at left side), and the corresponding values obtained by circuit simulation, considering different modulation index $(m=0.1,0.2,0.45$, columns from left to right side). In Fig. 5(a) is considered the case of load power factor $P F=1$, whereas in Fig. 5(b) is considered the case of load power factor $P F=-1$.

As expected, only odd-order harmonics appear also in simulation results, and harmonics with order multiple of three are practically missing (i.e., $3^{\text {rd }}, 9^{\text {th }}, 15^{\text {th }}$ ), according to (6), with the only exception of small numerical noises. Furthermore, the amplitude of the harmonic components are practically the same in all cases, with a good approximation, resulting to be independent of both the modulation index and load power factor.

\subsection{Five-phase inverters}

Actual load voltages of five-phase inverters can be expressed starting from the general expressions for $n$-phase inverters (7)-(10) developed in Section 3 by setting $n=5$, as

$v_{k}=v_{k}^{*}+u_{k}$,

being

$v_{k}^{*}=e_{k}^{*}-\left(e_{1}^{*}+e_{2}^{*}+e_{3}^{*}+e_{4}^{*}+e_{5}^{*}\right) / 5$,

and

$u_{k}=\Delta V_{d}\left\{-\operatorname{sign}\left(i_{k}\right)+\left[\operatorname{sign}\left(i_{1}\right)+\operatorname{sign}\left(i_{2}\right)+\operatorname{sign}\left(i_{3}\right)\right.\right.$
$\left.\left.+\operatorname{sign}\left(i_{4}\right)+\sin \left(i_{5}\right)\right] / 5\right\}$.

The time diagram $u_{k}(t)$ is depicted in Fig. 6 for the first phase $(k=1)$, considering five-phase sinusoidal balanced load currents, $i_{k}=I_{M} \sin \left[\omega_{o} t-(k-1) 2 \pi / 5\right]$.

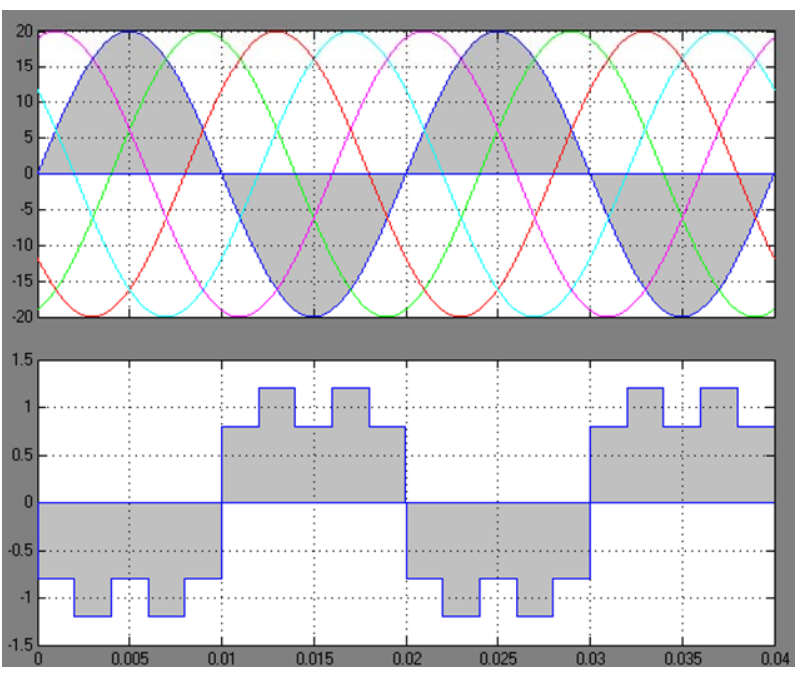

Fig. 6. Currents $i_{k}$ (top) and load voltage error $u_{1}$ (bottom, normalized with respect to $\Delta V_{d}$ ) for five-phase inverters. 


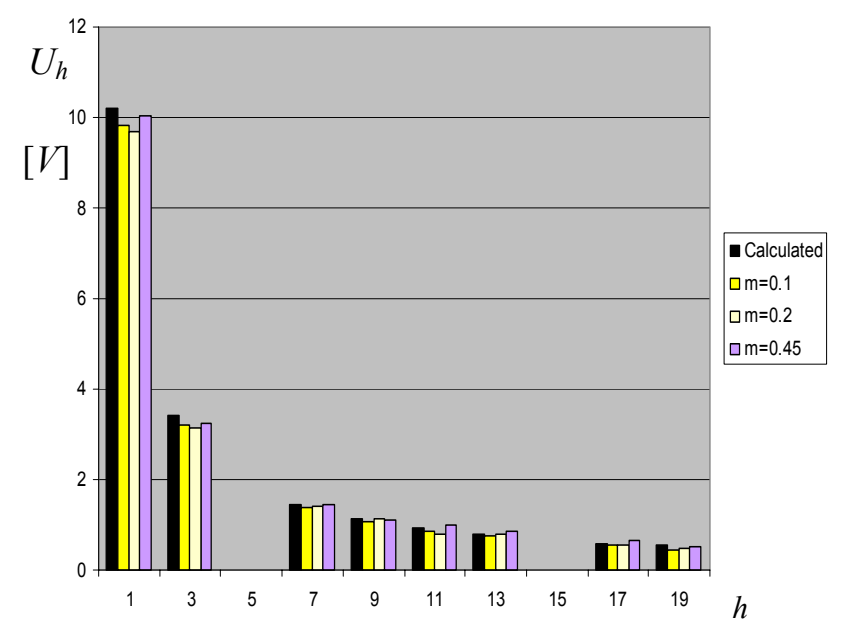

(a) $P F=1$

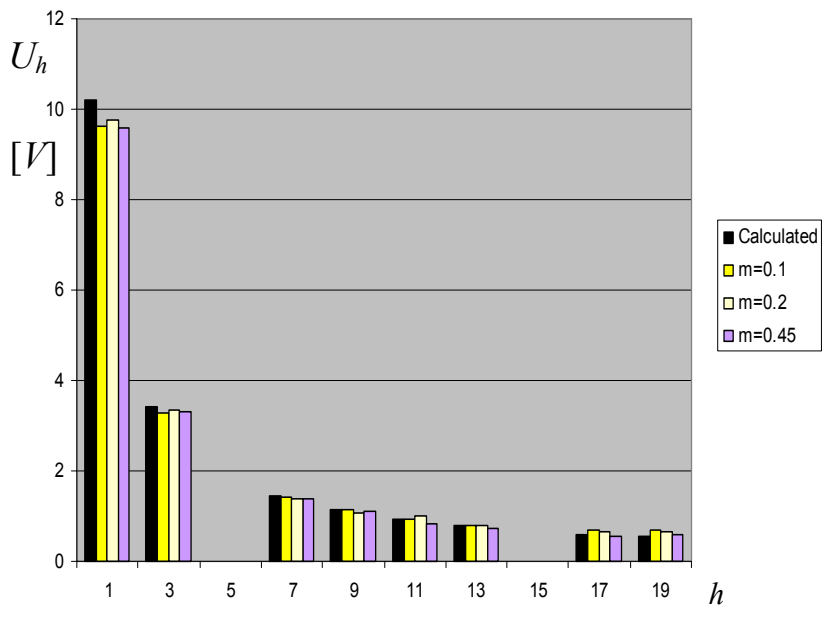

(b) $P F=-1$

Fig. 7. Harmonic spectrum of voltage error obtained by theory (calculated) and by circuit simulation for five-phase inverter with different modulation indexes and load power factors.

The resulting harmonic content of output voltage error can be expressed by setting $n=5$ in (11), leading to

$$
\begin{aligned}
& u_{k}=-\Delta V_{d} \frac{4}{\pi}\left\{\sin \left[\omega_{o} t-(k-1) \frac{2 \pi}{5}\right]+\frac{1}{3} \sin \left[3\left(\omega_{o} t-(k-1) \frac{2 \pi}{5}\right)\right]\right. \\
& +\frac{1}{7} \sin \left[7\left(\omega_{o} t-(k-1) \frac{2 \pi}{5}\right)\right]+\frac{1}{9} \sin \left[9\left(\omega_{o} t-(k-1) \frac{2 \pi}{n}\right)\right] \\
& \left.+\frac{1}{11} \sin \left[11\left(\omega_{o} t-(k-1) \frac{2 \pi}{5}\right)\right]+\frac{1}{13} \sin \left[13\left(\omega_{o} t-(k-1) \frac{2 \pi}{13}\right)\right]+\ldots\right\}
\end{aligned}
$$

Fig. 7 shows the harmonic spectrum calculated by (21) (black column at left side), and the corresponding values obtained by circuit simulation, considering different modulation index $(\mathrm{m}$ $=0.1,0.2,0.45$, columns from left to right side). In Fig. 7(a) is considered the case of load power factor $P F=1$, whereas in Fig. 7(b) is considered the case of load power factor $P F=-1$. As expected, also in this case, only odd-order harmonics appear in simulation results, and harmonics with order multiple of five are missing (i.e., $5^{\text {th }}$ and $15^{\text {th }}$ ), according to (21). Furthermore, amplitude of harmonic components are practically the same in all cases, resulting to be independent of both the modulation index and load power factor.

\subsection{Seven-phase inverters}

Also the actual load voltages of seven-phase inverters can be expressed starting from the general expressions for $n$-phase inverters (7)-(10) developed in Section 3 by setting $n=7$, as

$v_{k}=v_{k}^{*}+u_{k}$,

being

$v_{k}^{*}=e_{k}^{*}-\left(e_{1}^{*}+e_{2}^{*}+e_{3}^{*}+e_{4}^{*}+e_{5}^{*}+e_{6}^{*}+e_{7}^{*}\right) / 7$,

and

$$
\begin{aligned}
& u_{k}=\Delta V_{d}\left\{-\operatorname{sign}\left(i_{k}\right)+\left[\operatorname{sign}\left(i_{1}\right)+\operatorname{sign}\left(i_{2}\right)+\operatorname{sign}\left(i_{3}\right)\right.\right. \\
& \left.\left.+\operatorname{sign}\left(i_{4}\right)+\sin \left(i_{5}\right)+\operatorname{sign}\left(i_{6}\right)+\operatorname{sign}\left(i_{7}\right)\right] / 7\right\}
\end{aligned} .
$$

The time diagram $u_{k}(t)$ is depicted in Fig. 8 for the first phase $(k=1)$, considering seven-phase sinusoidal balanced load currents, $i_{k}=I_{M} \sin \left[\omega_{o} t-(k-1) 2 \pi / 7\right]$.

The resulting harmonic content of output voltage error can be expressed by setting $n=7$ in (11), leading to

$$
\begin{aligned}
& u_{k}=-\Delta V_{d} \frac{4}{\pi}\left\{\sin \left[\omega_{o} t-(k-1) \frac{2 \pi}{7}\right]+\frac{1}{3} \sin \left[3\left(\omega_{o} t-(k-1) \frac{2 \pi}{7}\right)\right]\right. \\
& +\frac{1}{5} \sin \left[5\left(\omega_{o} t-(k-1) \frac{2 \pi}{7}\right)\right]+\frac{1}{9} \sin \left[9\left(\omega_{o} t-(k-1) \frac{2 \pi}{n}\right)\right] \\
& \left.+\frac{1}{11} \sin \left[11\left(\omega_{o} t-(k-1) \frac{2 \pi}{5}\right)\right]+\frac{1}{13} \sin \left[13\left(\omega_{o} t-(k-1) \frac{2 \pi}{13}\right)\right]+\ldots\right\}
\end{aligned}
$$

Fig. 9 shows the harmonic spectrum calculated by (25) (black column at left side), and the corresponding values obtained by circuit simulation. Also in this case, different modulation index are considered ( $m=0.1,0.2,0.45$, columns from left to right side), whereas the load power factor is set to 1 and to -1 with reference to Fig. 7(a) and Fig.7(b), respectively.

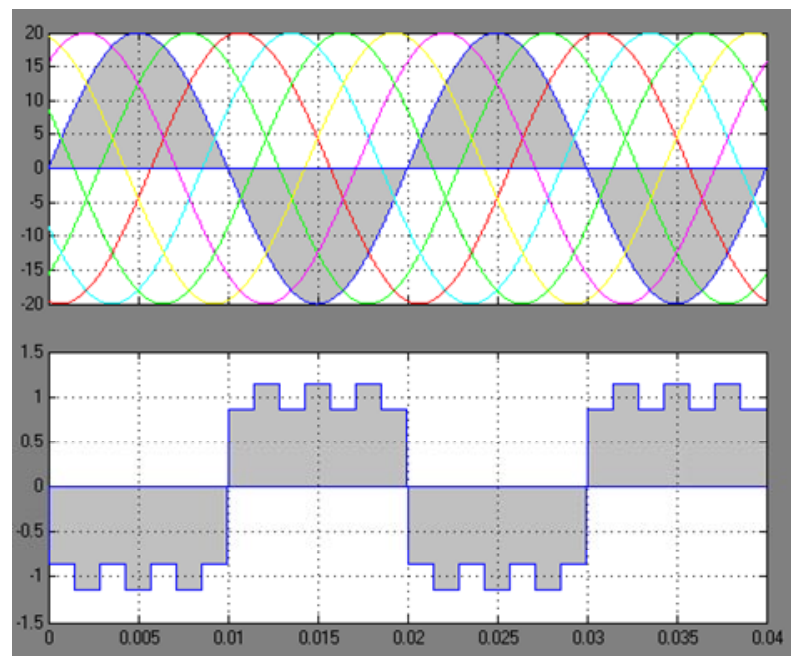

Fig. 8. Currents $i_{k}$ (top) and load voltage error $u_{1}$ (bottom, normalized with respect to $\Delta V_{d}$ ) for seven-phase inverters. 


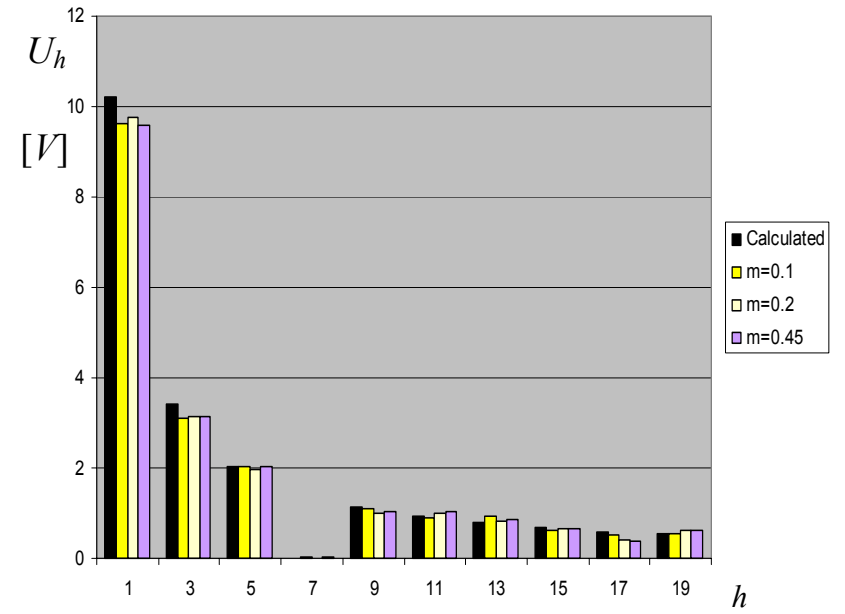

(a) $P F=1$

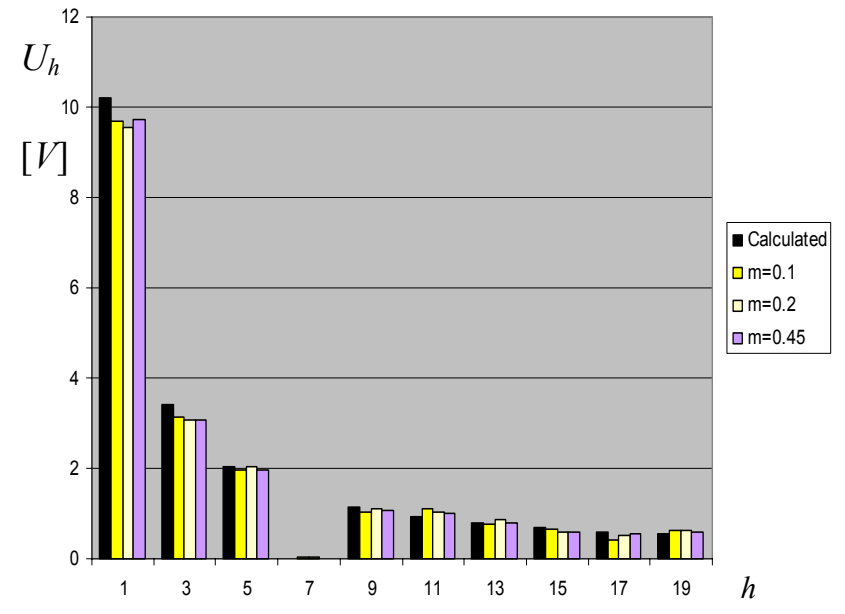

(b) $P F=-1$

Fig. 9. Harmonic spectrum of voltage error obtained by theory (calculated) and by circuit simulation for seven-phase inverter with different modulation indexes and load power factors.

As expected, also in this last case, only odd-order harmonics appear in simulation results, and harmonics with order multiple of seven are missing (here just $7^{\text {th }}$ can be noticed), according to (25), with the only exception of small numerical noises. Furthermore, amplitude of harmonic components are practically the same in all cases, resulting to be independent of both the modulation index and load power factor.

\section{Conclusion}

The switching time delay in a PWM inverter has effects on inverter operation. It causes a decrease in the fundamental component of output voltages and it introduces low-order harmonics. This paper initially presents a brief review of the dead-time effects in three-phase inverter and, further on, an analytical extension to $n$-phase inverters, analyzing the loworder harmonics introduced in output phase voltages. Using numerical circuit simulations it has been shown that the effect on output voltage of three- five- and seven-phase inverters, as examples of $n$ phases, is in good agreement with proposed analytical developments.

\section{References}

[1] Seung-Gi Jeong and Min-Ho Park, "The Analysis and Compensation of Dead-Time Effects in PWM Inverters," IEEE Trans. on Ind. Electronics, vol. 38, no. 2, April 1991, pp. 108-114.

[2] D. Leggate, R.J. Kerkman, "Pulse-based dead-time compensator for PWM voltage inverters," IEEE Trans. on Industrial Electronics, vol. 44, no. 2, April 1997, pp. 191-197.
[3] T. Sukegawa, K. Kamiyama, K. Mizuno, T. Matsui and T. Okuyama, "Fully Digital, Vector-Controlled PWM VSI-Fed ac Drives with an Inverter Dead-Time Compensation Strategy," IEEE Trans. on Ind. Appl., vol. 21, no. 3,May/June 1991, pp. 552-559.

[4] A. Muiioz-Garcia T.A. Lipo, "On-line dead time compensation technique for open-loop PWM-VSI drives," proc. of $13^{\text {th }}$ Applied Power Electronics Conference and Exposition, APEC, vol. 1, Feb 1998, pp. 95-100.

[5] L.Chen, F.Z.Peng "Dead-time elimination for voltage source inverters," IEEE Trans. on Power Electronics, vol. 23, no. 2, March 2008, pp. 574-580.

[6] E.Levi, R.Bojoi, F.Profumo, H.A.Toliyat, S.Williams on "Multiphase induction motor drives - a technology status review," IET Electr. Power Appl., vol. 1, no. 4, July 2007, pp. 489-516.

[7] M.Jones, D.Dujic, E.Levi S.N.Vukosavic, "Dead-Time Effects in Voltage Source Inverter Fed Multi-Phase AC Motor Drives and Their Compensation," in Proc. of $13^{\text {th }}$ European Conf. on Power Electronics and Applications, EPE, Barcelona (Spain), 8-10 Sept. 2009.

[8] K. Oka, H. Enokijima, H. Kubota, K. Matsuse, “Analysis and Compensation Method of Voltage Error by DeadTime with Five-Leg Inverter for Two-AC Motor Independent Drives," in Proc. of Energy Conversion Congress and Expositions, IEEE-ECCE, San Jose-CA (USA), Sept. 20-24, 2009, pp. 869-876.

[9] S.H. Hwang and J.M. Kim, "Dead Time Compensation Method for Voltage-Fed PWM Inverter," IEEE Transactions on energy conversion, vol. 25, no. 1, March 2010, pp. 1-10. 